This is the submitted version of the article:

Pérez-Tomás A., Chikoidze E., Jennings M.R., Russell S.A.O., Teherani F.H., Bove P., Sandana E.V., Rogers D.J.. Wide and ultra-wide bandgap oxides: Where paradigm-shift photovoltaics meets transparent power electronics. Proceedings of SPIE - The International Society for Optical Engineering, (2018). 10533. 105331Q: - . 10.1117/12.2302576.

Available at: https://dx.doi.org/10.1117/12.2302576 


\title{
Wide and ultra-wide bandgap oxides: where paradigm-shift photovoltaics meets transparent power electronics
}

\author{
Amador Pérez-Tomás ${ }^{* a}$, Ekaterine Chikoidze ${ }^{\mathrm{b}}$, Michael R. Jennings ${ }^{\mathrm{c}}$, Stephen A. O. Russell ${ }^{\mathrm{c}}$, \\ Ferechteh H. Teherani ${ }^{\mathrm{d}}$, Philippe Bove ${ }^{\mathrm{d}}$, Eric V. Sandana ${ }^{\mathrm{d}}$, and David J. Rogers ${ }^{\mathrm{d}}$ \\ ${ }^{a}$ Catalan Institute of Nanoscience and Nanotechnology (ICN2), CSIC and The Barcelona Institute of \\ Science and Technology, Campus UAB, Bellaterra, 08193 Barcelona, Spain; ${ }^{\text {}}$ Groupe d'Etude de la \\ Matière Condensee (GEMaC), Université de Versailles Saint Quentin en Y. - CNRS, Université

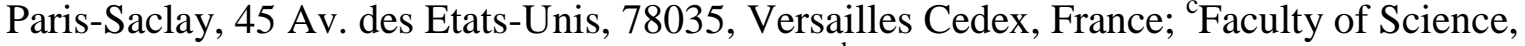 \\ University of Warwick, Coventry CV4 7AL, U.K; ${ }^{\mathrm{d}}$ Nanovation, 8 route de Chevreuse, 78117 \\ Châteaufort, France.
}

\begin{abstract}
Oxides represent the largest family of wide bandgap (WBG) semiconductors and also offer a huge potential range of complementary magnetic and electronic properties, such as ferromagnetism, ferroelectricity, antiferroelectricity and high-temperature superconductivity. Here, we review our integration of WBG and ultra WBG semiconductor oxides into different solar cells architectures where they have the role of transparent conductive electrodes and/or barriers bringing unique functionalities into the structure such above bandgap voltages or switchable interfaces. We also give an overview of the state-of-the-art and perspectives for the emerging semiconductor $\beta-\mathrm{Ga}_{2} \mathrm{O}_{3}$, which is widely forecast to herald the next generation of power electronic converters because of the combination of an UWBG with the capacity to conduct electricity. This opens unprecedented possibilities for the monolithic integration in solar cells of both self-powered logic and power electronics functionalities. Therefore, WBG and UWBG oxides have enormous promise to become key enabling technologies for the zero emissions smart integration of the internet of things.
\end{abstract}

Keywords: Ultra Wide Bandgap Semiconductors, Oxides, Solar Cells, Ferroelectricity, Power Electronics.

\section{INTRODUCTION}

Owing their catalytic activity and semiconductor properties, a very relevant class of oxides for energy-related applications are the transition metal oxides (TMO). These are compounds composed of oxygen atoms bound to a metal with a partially filled $d$ sub-shell. The basic structural units of transition element oxides are an $\mathrm{MO}_{6}$ octahedron and $\mathrm{MO}_{4}$ tetrahedron. The metal- $d$ orbitals $\left(\mathrm{M}_{d}\right)$ overlap with the ligand $2 p$ orbitals $\left(\mathrm{O}_{2 p}\right)$ forming molecular orbitals. In a usual TMO therefore the conduction band is the $d$ band and the valence band is the $p$ band. Most undoped metal oxides (such as $\mathrm{Al}_{2} \mathrm{O}_{3}, \mathrm{SnO}_{2}, \mathrm{TiO}_{2}, \mathrm{In}_{2} \mathrm{O}_{3}, \mathrm{Cu}_{2} \mathrm{O}, \mathrm{WO}_{3}, \mathrm{ZnO}$ or $\left.\mathrm{NiO}\right)$ have a much wider bandgap than that of silicon $(1.12 \mathrm{eV})$ and are generally insulating at room temperature if they are stoichiometric and undoped. Some TMO can, however, be both transparent and highly conductive (i.e. transparent conducting oxides (TCOs)) when degenerately doped (e.g. $\mathrm{In}_{2} \mathrm{O}_{3}$, $\mathrm{SnO}_{2}$ or $\mathrm{ZnO}$ ). Such TCOs are currently the standard choice for use in transparent electrode applications [1] and are also hugely important for information and communication technologies such as displays, touch screens or light emitting diodes [2].

TCOs typically have bandgaps between about 3.1 and $3.7 \mathrm{eV}$. Amongst the TMO with even larger bandgaps, gallium oxide, $\beta-\mathrm{Ga}_{2} \mathrm{O}_{3}$, $(\mathrm{Eg} \sim 4.9 \mathrm{eV})$ stands out as being the only one in which can be degenerately doped (as recently demonstrated by Look, Leedy and co-workers [3]). Because it has by far the widest band gap among the practical TCOs

* amador.perez@icn2.cat; phone + 34937372 649; fax + 34936917 640; icn2.cat 
it is transparent much further into the UV (down to $\sim 260 \mathrm{~nm}$ ) and it, therefore, provides a unique transparency to the whole solar spectrum which can offer new perspectives for photonic and photovoltaic applications [4]. Furthermore, owing to its extreme bandgap, doping control, relatively high mobility and high critical electric field ( $~ 8 \mathrm{MV} / \mathrm{cm})$, ultrawide bandgap (UWBG) $\mathrm{Ga}_{2} \mathrm{O}_{3}$ is emerging as the platform of choice to succeed silicon, silicon carbide and gallium nitride in the fourth generation of power electronic devices [5]. Recent breakthroughs in materials quality have led, therefore, to $\beta-\mathrm{Ga}_{2} \mathrm{O}_{3}$ becoming the current object of intense research for applications such as a transparent conductor, transparent field-effect transistors, photodetectors, and power electronics devices [6],[7]. Single crystal $\mathrm{Ga}_{2} \mathrm{O}_{3}$ is $\mathrm{known}$ to form five polymorphs, labelled as $\alpha, \beta, \gamma, \delta, \varepsilon$. Amongst these, the $\beta$-phase is the most stable, and the other polymorphs are meta-stable in nature.
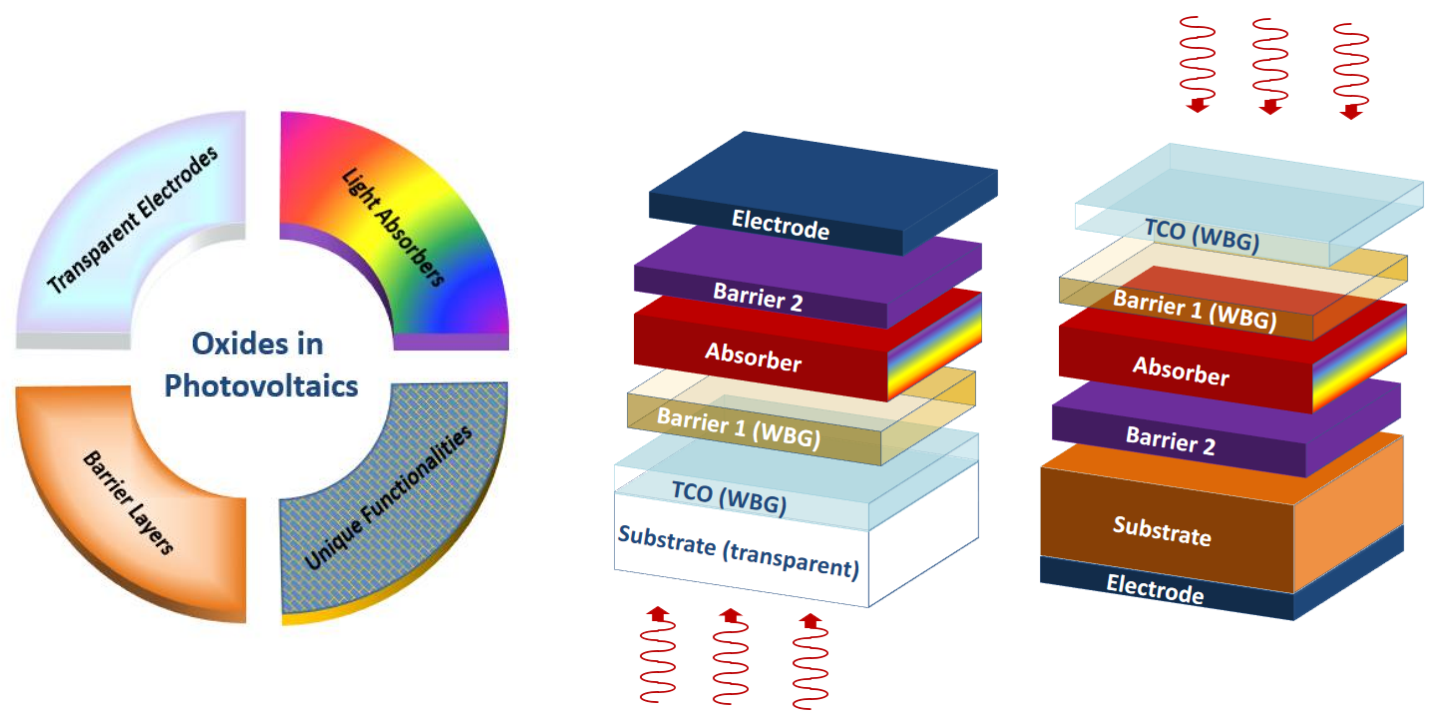

Figure 1. Oxides are used widely in solar cells (as insulators, semiconductors and conductors) and they generally deliver lower cost and better device stability. Although there are a number of thin-film photovoltaic technologies (i.e. a-Si, CIGS, CdTe, CZTS, OPV, HOIP, etc) the basic solar cell structure is a sandwich of a light harvester layer (depleted of free carriers) in between two carrier extraction layers, with the final goal of maximizing the conversion of light into electricity (the power conversion efficiency (PCE)). The oxide layer(s) may act as transparent conductive electrodes, light absorbers, transport (or barrier) layers or bring other functionalities such as ferroelectricity. Adapted from [28] Copyright (C) 2018 Elsevier Inc. All rights reserved.

Other complex TMO WBG materials are known for offering a wide range of magnetic and electronic behaviours, such as ferromagnetism, ferroelectricity, antiferroelectricity and high-temperature superconductivity. These interesting property sets often come from their strongly correlated electrons in $d$ or $f$ orbitals. A nonzero spontaneous polarization is present in many crystals with a polar space group. However, ferroelectricity necessarily implies the capability of rotational diffusion of orientable dipoles under an applied electric field. Thus, most polar crystals such as quartz or wurtzite structures (e.g. $\mathrm{GaN}$ or $\mathrm{ZnO}$ ) are not ferroelectric. In practice, the orientable spontaneous polarization is due to a particular atomic arrangement of ions in the crystal structure. A small symmetry-breaking distortion of a highersymmetry reference configuration enables different discrete states of polarization. Polar displacements of the atoms in the unit cell form, therefore, the basis of ferroelectricity. The most studied family of ferroelectrics is the perovskite oxides. These are a large set of materials which share the composition $\mathrm{ABO}_{3}$, where $\mathrm{A}$ and $\mathrm{B}$ represent either discrete cation elements or a mixture of two or more such elements (or vacancies). $\mathrm{BaTiO}_{3}(\mathrm{BTO})$ and $\mathrm{Pb}(\mathrm{Zr}, \mathrm{Ti}) \mathrm{O}_{3}(\mathrm{PZT})$ are prototypical examples. Undoubtedly, the PZT family (with a bandgap of $\sim 3.5-3.8 \mathrm{eV}$ ) is the most important and versatile composition base for ceramic piezoelectric elements and it is a component of many consumer products nowadays [8].

Therefore, wide and ultra-wide bandgap oxide technologies can be viewed as a melting pot for unique/combined/emergent property sets. The recent rise of the UWBG semiconducting gallium oxide adds to this in providing a potential competitive advantage over current power electronic devices based on $\mathrm{Si}, \mathrm{SiC}$ and $\mathrm{GaN}$. This opens unprecedented opportunities for smart monolithic integration of systems for the generation and conversion of energy together with new transparent information and communication technologies which have been completely detached from 
power electronics up till now. In this paper, we succinctly present some of our recent achievements on the way towards this inspiring future.

\section{OXIDES IN PHOTOVOLTAICS}

\subsection{Absorbers, transparent electrodes and barriers}

A solar cell is a device that converts photons into usable electric energy by means of the photovoltaic effect. Although there are a number of photovoltaic technologies [9], the basic solar cell structure is a sandwich of a light harvester layer (depleted of free carriers) in between two carrier extraction layers. The final goal is to maximize the light conversion into electricity (the power conversion efficiency (PCE)) (Fig. 1). Oxides are used widely in solar cells (e.g. as insulators, semiconductors and conductors) and are generally adopted because they deliver performance advantages, a lower cost and larger device stability. As shown in Fig. 1, the oxide layer is present in several kinds of solar cells and is multifunctional (e.g. as transparent conductive electrodes, as light absorbers, as transport layers or bringing new functionalities into the structure such as ferroelectricity).

\begin{tabular}{|c|c|c|c|c|c|c|c|}
\hline Solar Cell Type & $\begin{array}{l}\text { Role } \\
\text { Oxide }\end{array}$ & $\begin{array}{c}\text { Ic } \\
{\left[\mathrm{mW} / \mathrm{cm}^{2}\right]}\end{array}$ & $\begin{array}{l}V_{o c} \\
{[V]}\end{array}$ & $\begin{array}{c}J_{\mathrm{ac}} \\
{\left[\mathrm{mA} / \mathrm{cm}^{2}\right]}\end{array}$ & FF & $\begin{array}{l}\text { PCE } \\
{[\%]}\end{array}$ & Ref. \\
\hline \multicolumn{8}{|c|}{ All-Oxide Solar Cells } \\
\hline $\mathrm{Cu}_{2} \mathrm{O}$ & $\begin{array}{c}\boldsymbol{p}-\boldsymbol{n} \\
n-\mathrm{Zn}_{1-x} \mathrm{Ge}_{\mathrm{x}} \mathrm{O}\end{array}$ & 100 AM 1.5 & 1.10 & 11.00 & 0.60 & 8.10 & [10] \\
\hline Multiferroic & $\begin{array}{l}\text { Absorber } \\
\mathrm{Bi}_{2} \mathrm{FeCrO}_{6}\end{array}$ & 100 AM1.5 & 0.84 & 20.60 & 0.47 & 8.10 & [11] \\
\hline Oxide Stack & $\begin{array}{c}\text { Absorber } \\
\mathrm{BiFeO}_{3} / \mathrm{ZnO}\end{array}$ & 100 AM 1.5 & 0.64 & 12.47 & 0.50 & 3.98 & [12] \\
\hline \multicolumn{8}{|c|}{ Non-Shockley=Queisser Limited Oxide Solar Cells } \\
\hline Ferroelectric & $\begin{array}{l}\text { Absorber } \\
\mathrm{Pb}(\mathrm{Zr}, \mathrm{Ti}) \mathrm{O}_{3}\end{array}$ & $\begin{array}{l}\text { Near UV } \\
(365 \mathrm{~nm})\end{array}$ & 4.00 & $2 \times 10^{-8}$ & & & [13] \\
\hline Multiferroic & $\begin{array}{c}\text { Absorber } \\
\text { BiFeO }_{3}\end{array}$ & White Light & 16.00 & 0.10 & & & [14] \\
\hline Antiferroelectric & $\begin{array}{c}\text { Absorber } \\
\mathrm{PbZrO}_{3}\end{array}$ & $\begin{array}{l}\text { Near UV } \\
(365 \mathrm{~nm})\end{array}$ & 120.00 & $1 \times 10^{-4}$ & & & [15] \\
\hline \multicolumn{8}{|c|}{ Ferroelectric Oxide Barriers in Thin-Film Solar Cells } \\
\hline $\begin{array}{l}\text { Organic } \\
\text { P3HT:PCBM }\end{array}$ & $\begin{array}{c}E T L \\
\mathrm{~Pb}(\mathrm{Zr}, \mathrm{Ti}) \mathrm{O}_{3}\end{array}$ & 100 AM1.5 & 0.51 & 7.07 & 0.32 & 1.18 & [16] \\
\hline $\mathrm{a}-\mathrm{Si}$ & $\begin{array}{c}p-n \\
n-\mathrm{Pb}(\mathrm{Zr}, \mathrm{Ti}) \mathrm{O}_{3}\end{array}$ & 100 AM1. 5 & 1.36 & 3.07 & 0.3 & 1.25 & [17] \\
\hline $\mathrm{Cu}_{2} \mathrm{O}$ & $\begin{array}{c}p-n \\
n-\mathrm{Pb}(\mathrm{Zr}, \mathrm{Ti}) \mathrm{O}_{3}\end{array}$ & $100 \mathrm{AM} 1.5$ & 0.42 & 4.80 & 0.28 & 0.57 & [18] \\
\hline
\end{tabular}
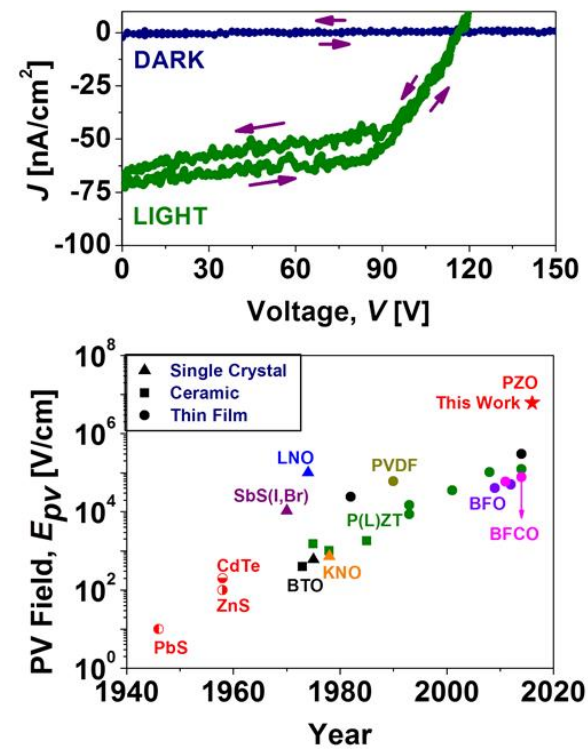

Figure 2. Summary (Refs. 10-19) of some relevant oxide-based solar cells. All-oxide solar cells are those where absorbers and barriers are made of oxide materials. There is a special class of non-centrosymmetric solar cells in which the photovoltaic effect is not based on $p$ - $n$ junctions but another photo-generation mechanisms called the bulk photovoltaic effect. The mechanism behind this kind of cell is not subject to the Shockley-Queisser efficiency limit and, therefore, these solar cells can present above bandgap photovoltages. Such anomalous photovoltaic effects are particularly strong in functional oxides such as ferroelectrics, multiferroics and antiferroelectrics. Antiferroelectric thin-films can produce unprecedented photo-generated fields in excess of $6 \mathrm{MV} / \mathrm{cm}$, which is the largest photovoltaic field ever seen in any material (adapted from [15] Copyright Wiley-VCH Verlag GmbH \& Co. KGaA. Reproduced with permission.). Functional oxides can also be implemented in the context of other solar cells such as organic bulk heterojunctions (P3HT:PCBM), amorphous silicon $(a-\mathrm{Si})$, copper oxide solar cells $\left(\mathrm{Cu}_{2} \mathrm{O}\right)$ or hybrid organic-inorganic halide perovskites.

Owing to the large (and tuneable) bandgap energy range covered by metal oxides, there are many oxides which are potentially suitable as light harvesters. Nevertheless, since silicon and other III-V semiconductors have historically received much more attention, only a few MOs have been seriously investigated as the photon absorber. The photovoltaic junction required to create the internal built-in field to separate electron and holes can be a Schottky junction, a $p$ - $n$ homojunction or a $p$ - $n$ heterojunction, the last one of which currently delivers the highest PCE. The $p$ type absorber itself defines the photo-physics (absorption coefficient, direct or indirect bandgap, bandgap energy, etc.) 
and the transport properties (electrical conduction, electron and hole mobilities, minority and majority carrier transport characteristics, etc.) [20]. Among metal oxides the copper oxides $(\mathrm{Cu}-\mathrm{O})$ are the most popular absorber material by far. There are several stable binary oxide phases of copper oxides including $\mathrm{Cu}_{2} \mathrm{O}$ (cuprite or cuprous oxide), $\mathrm{CuO}$ (tenorite or cupric oxide) and $\mathrm{Cu}_{4} \mathrm{O}_{3}$ (paramelaconite). Thanks to this choice the $\mathrm{CuO}_{\mathrm{x}}$ bandgap can be tuned in the range between 1.4-2.2 eV. Although $\mathrm{CuO}$ was used to make the first photovoltaic cells, the use of copper oxides only recently regained interest fueled by the potential for light-to-electricity power conversion improvement (PCE has raised up to 8\%) [10] and the use as a photocathode in photoelectrochemical cells [21],[22].

Apart from the absorber, any solar cell in a vertical architecture requires at least one transparent conductive electrode in order to allow the sunlight to penetrate into the core light absorbing layers. At the time being, the industry standard TCOs used are largely limited to the post-transition metal oxides $\mathrm{In}_{2} \mathrm{O}_{3}, \mathrm{SnO}_{2}$ and $\mathrm{ZnO}$ (plus various ternary and quanternary mixtures/alloys) [1]. The excellent metal-oxide orbital overlap in these structures gives rise to low electron effective masses and therefore high electron mobilities. This together with their high dopability and wide bandgaps, is what makes these three host structures the most important for TCO applications. A high conductivity in these TCO is achieved by increasing the oxide carrier concentration (e.g. doping) while maintaining sufficiently high carrier mobility; an increase in doping tends to induce a reduction in the mobility because of the scattering of free charge carriers at ionized impurities. In other words, whereas the maximum carrier concentration is limited by the dopant solubility in the host material (around $\sim 10^{21} \mathrm{~cm}^{-3}$ ), carrier mobility is limited by ionized impurity scattering, a universal process in degenerately doped semiconductors [23]. Much research has gone into investigating a number of dopant elements; in $n$ type TCOs, and it is usually substitutional cation dopants which provide excess electrons at the dopant site.

Another key factor in the adoption of oxide TCOs is that they are compatible with the strict manufacturing requirements of large-scale, large-volume, flexible, low cost and disposable/reusable devices [24]. These constraints are particularly relevant for thin-film photovoltaics (e.g. organic - OPVs -, plastic - PSCs -, dye sensitized - DSSCs - or halide perovskite - HPSCs - solar cells) where extremely large-scale, large volume fabrication requires low cost fabrication in order to be competitive with dominant Si-based photovoltaic technologies. In these kinds of solar cells, the carrier transport layer (or barrier layer) may also be an oxide thin-film that (i) tunes the Schottky barrier alignment and, (ii) selects the majority carriers in order to avoid recombination. This layer also works as either the hole transport layer, HTL, (or electron barrier layer) and the electron transport layer, ETL, (or hole barrier layer). Oxide barriers in general enhance the stability of such solar cells [25].

\subsection{Functional oxides: Ferro-, multiferro- and antiferro- photovoltaics}

Ferroelectric photovoltaics is a growing field of research and is the class of materials for which the bulk photovoltaic effect (BPE) is strongest [26]. In the BPE a piezo field separates light induced charge carriers and generates a photovoltaic current. This anomalous photovoltaic effect is due to the asymmetry of the lattice in non-centrosymetric crystals. While the photovoltage for a single $p-n$ junction based solar cell (and thus the ultimate PCE) is limited by the bandgap (as explained by Shockley-Queisser [27]), it can be orders of magnitude higher for BPE devices, as shown in Fig. 2. To increase the photovoltage per individual junction in a solar cell in this way would be very useful to reduce interconnections or to simplify the integration into AC modules, perhaps paving the way to avoid boost converters or similar. In spite of the fact that any non-centrosymmetric media can theoretically display bulk photovoltaic current, however, only a very limited number of ferroelectric devices have been reported to produce above bandgap voltages thus far [28]. Indeed, above bandgap BPE photovoltages have proven particularly challenging to achieve in devices with a vertical architecture exposed to indoor or solar (outdoor) light. As a result, above bandgap operation has not yet been implemented in solar cells. Furthermore, while there is a developed theory for explaining the origin of the bulk photovoltaic current (which is useful for predicting theoretical giant BPE-currents for some materials), there is no analogous body of knowledge for BPE-photovoltage.

In 2016 we reported large above bandgap voltages $(120 \mathrm{~V})$ and the largest photovoltaic field (more than $6 \mathrm{MV} / \mathrm{cm}$ ) ever observed for any material in antiferroelectric $\mathrm{PbZrO}_{3}$ (PZO) thin films [15]. Antiferroelectrics are generally centrosymmetric (space group Pbam), but application of a suitably large external field can cause a transition from their antipolar ground state to a polar phase. Though removing the external field should in principle result in a return to the 
antipolar state and thus the loss of any above-bandgap photovoltage, switching under illumination unexpectedly resulted in the pinning of the polar state. The bulk photovoltaic effects have generally produced only very low currents thus far [29] as would be expected based on the relatively insulating nature of the media. It has been proposed that innovative approaches such as surface engineering, thickness optimization or a nanorod architecture might deliver improved currents. Very recently, a tip enhanced bulk photovoltaic effect has been reported to beat the Shockley-Queisser limit opening new possibilities at the nanoscale [30].

Ferroelectric oxides possess additional useful features in their switchable properties (a changeable direction of current and voltage by polarization switching) and an anomalous photovoltaic effect that can generate huge above bandgap photovoltages. Nevertheless, their inherently low photocurrents (in the range of $n A-\mu A / \mathrm{cm}^{2}$ ) have resulted in poor overall photovoltaic efficiency. As shown in the table of Fig. 2, a way to improve the photovoltaic current of FE-oxide solar cells is through the combination with organic, inorganic or hybrid semiconductor light absorbers such as $\mathrm{Cu}_{2} \mathrm{O}$ [18], a-Si [17], $\mathrm{ZnO}$ [12] or $\mathrm{MAPbI}_{3}$ (methyl-ammonium lead iodide based halide perovskite) [19]. Ferroelectrics can be exploited not just as photovoltaic absorbing materials in their own right, but also as (switchable) charge transport layers within other photoelectronic devices as shown below.

\subsection{The solar transistor or Solaristor}
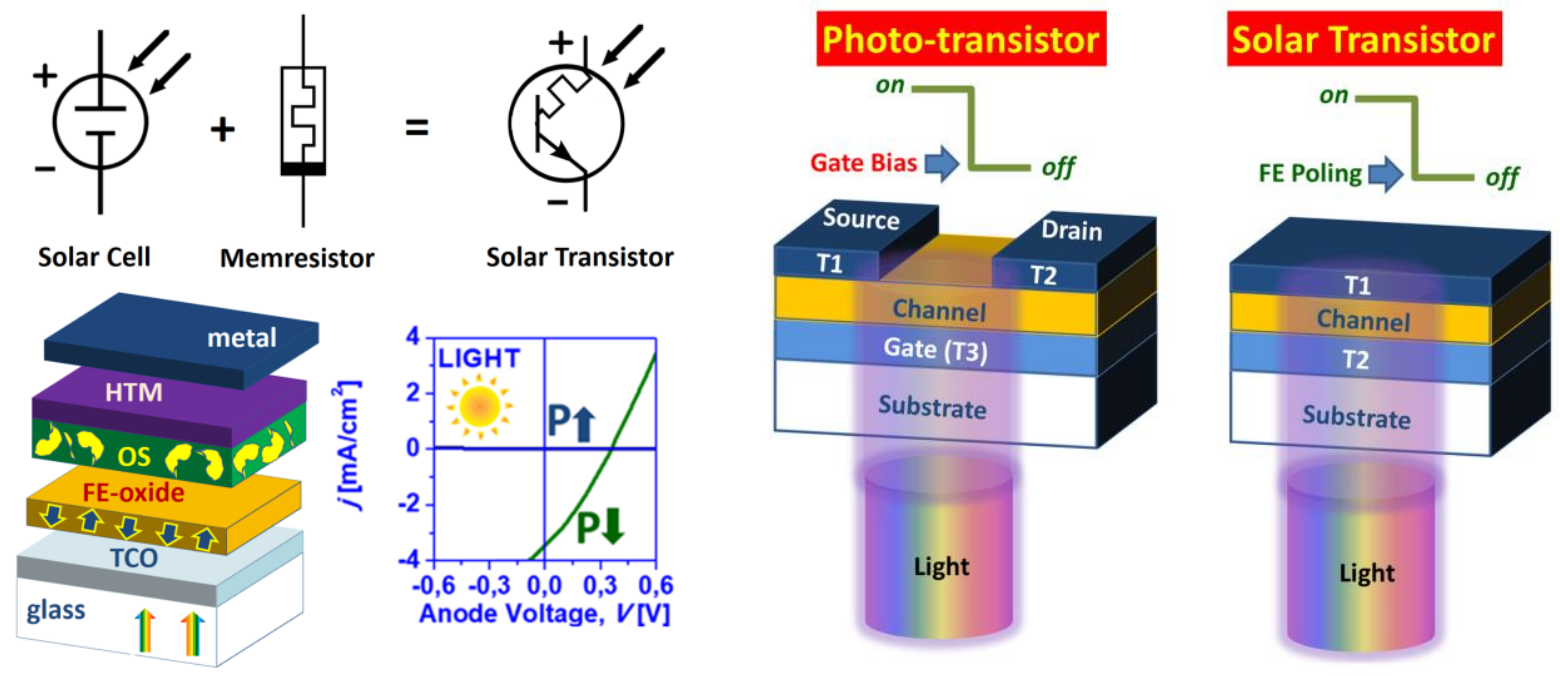

Figure 3. The new solaristor device concept that merges in a photo-gated two-electrode geometry the switching capability of transistors, the non-volatility of ferroelectric memories, and the autonomy of solar cells. Transistors require an external voltage source and a third terminal, which is known as a "gate". Self-powered solar cells in contrast have only two electrodes but do not switch. By combining an organic bulk heterojunction absorber and a ferroelectric electron transport layer we demonstrate the new solar transistor concept. Adapted from [16] Copyright Wiley-VCH Verlag GmbH \& Co. KGaA. Reproduced with permission.

In the context of switchable photovoltaic interfaces, ferroelectric oxides add new functionalities to the structure. Transistors switch a semiconductor conductive state (or on-state) and an insulator state (or off-state) by means of a third additional terminal known as gate [31]. An external bias between their two flow electrodes is required for channel carriers to move, and this bias represents an undesirable, yet unavoidable, energy consumption. Harvesting the photon energy, a photovoltaic junction would already act as a self-powered current source, but incipient photovoltaic switches do not have a stable low energy consumption state [16]. A phototransistor, photo-switch or photo-FET [32] can be defined as a three-terminal device whose output can be simultaneously and independently controlled by light or voltage. Ideally, the phototransistor concept should be integrated into a vertical (sandwich-like) two-terminal device for higher density miniaturization while keeping a normally-off state for better dissipation efficiency and easier control. A reliable, cleanroom-less, low cost two-terminal phototransistor would represent a paradigm shift for the next generation of 
sustainable embodiments such as photodetectors, smart windows, flexible detector systems and optical memories. Nevertheless, such a device is unconventional and challenging since a photovoltaic semiconductor Schottky or $p-n$ junction does not switch as internal fields and chemical potentials are not bi-stable.

Very recently, a transistor effect has been evidenced by combining organic P3HT:PCBM-based solar cells with a ferroelectric layer which acts as a switchable electron transport medium [16]. A photocurrent variation of various orders of magnitude can be obtained by varying the ferroelectric polarization of the PZT layer and the band alignment in the device. This finding expanded the switching capabilities of previous devices combining ferroelectric layers with photovoltaic devices, demonstrating a conductivity that can be switched by voltage and gated by light. Under sunlight illumination, the absorbing organic bulk heterojunction acts a self-powered source of photo-generated electrons and holes that are driven towards their respective electrodes. Conventional photodiodes do not switch, but here, the modification of the electron transport layer barrier offsets due to the stable gating effect of the ferroelectric polarization, which enables the on-off switching of the photodiode. As an additional advantage, the conventional phototransistor's footprint and interconnection complexity are greatly reduced by moving from the standard in-plane three-electrode architecture to a vertical, two-electrode photodiode-like architecture (Fig. 3). We foresee several routes to improve the device performance. On one hand, the solar transistor PCE may be increased by using alternative and more efficient light absorbers such as halide perovskites. Ferroelectric oxide thin-films can also deliver improved performances in alternative ways. For instance, ferroelectric thin-films with more pronounced band-offsets, for example, can in principle improve the on/off ratio of the device as well as the transistor's photocurrent and PCE. In addition, narrower bandgap ferroelectrics such as $\mathrm{BiFeO}_{3}$ or $\mathrm{BiCrFeO}_{3}$ can theoretically contribute to the light harvesting; such visible bandgap ferroelectric oxides could act as the light absorber itself in an all-oxide solution. Alternatively, ferroelectric oxides with even wider bandgaps than PZT (i.e. more solar blind) would allow all the solar radiation to pass through the electron transport layer, and thus reach the active layers without attenuation. While the new device concept is described as a photo-transistor, its' design is multifunctional and may be used for other photonic applications. For example, the device is also a photonic ferroelectric random-access memory (FRAM) where the bits are written via an electrical pulse, but read non-destructively using a light pulse that excites a high current in the on state, and a low current in the off state. In any case, the solaristor opens new and exciting synergistic possibilities at the frontier of research into ferroelectrics, photonics, electronics and photovoltaics.

\section{OXIDES IN POWER ELECTRONICS}

\subsection{Wide bandgap electronic materials: The semiconductor platform, gate insulator and passivation layer}

Renewable energy is becoming a widely accepted and mainstream source of energy where power electronics is a key enabler of its' successful integration. Power electronics is the application of solid-state electronics to the control and conversion of electric power. Indeed, a key factor in the efficient transmission and conversion of low-carbon electrical energy is the improvement in the efficiency of power electronic devices. Silicon has been the most successful electronic material of the 20th century. The rate of progress since the first silicon solid-state transistor has been enormous, with the number of transistors on a single chip growing from a few thousand in the earliest integrated circuits to more than two billion today. Nevertheless, successful information and communication silicon electronics exhibit important drawbacks in energy conversion systems: Si based devices performance degrades badly at high temperatures, Si a low intrinsic breakdown field $(0.3 \mathrm{MV} / \mathrm{cm})$ and (as a low (indirect) bandgap material $(\mathrm{Eg} \sim 1.12 \mathrm{eV})$ ) silicon is not transparent to visible light and, therefore, not very suitable for future optoelectronics [33].

As an alternative to $\mathrm{Si}$ there is a new generation of WBG semiconductors which have the capacity to operate at higher voltages, temperatures and switching frequencies with greater efficiencies compared to existing Si devices. This characteristic results in less losses and enables significantly reduced volume due to decreased cooling requirements and smaller passive components contributing to overall lower system cost. WBG (in the context of power electronic devices) usually denotes semiconductors with a bandgap that is significantly larger than silicon (by a factor of two at least). As mentioned above, oxides are the family of materials which presents the largest selection of WBG semiconductors. Moreover, many oxide layers have proven robustness for use in power electronic devices because they have already been 
used extensively as gate insulators and passivation layers (Fig. 5). Rectifiers (diodes) and switches (transistors) [36] are the basis of any DC, AC or RF power converter. In rectifiers, which are either based on a Schottky barrier or a p-i-n junction, a surface capping oxide layer provides the passivation required to maximize the voltage breakdown of the structure [37]. In transistors, the gate oxide is a fundamental part of the structure that has a double role. On one hand, it provides the required insulation between the gate terminal and the channel carriers. On the other hand, it depletes or accumulates charges at oxide/semiconductor interface which is the basis of the transistor effect (Fig. 5). Here the quality of the oxide interface is capital in that an interface with low defect density is required in order to avoid reduction of the channel mobility. The low channel mobility of metal-oxide-semiconductor transistors (MOSFETs) is a relevant problem in many WBG semiconductor systems, particularly in $\mathrm{SiC}$ and GaN [38],[39]. Gate oxides are also present in high electron mobility transistors (HEMTs), where the channel electrons are buried in the low doped wide bandgap semiconductor, and hence primarily free from interface scattering. However, a gate insulator is required for power HEMTs otherwise the gate current is impractically large. GaN HEMTs are becoming an important device for mid-power range $(600-1200 \mathrm{~V})$ in applications such as the photovoltaic DC-AC power inverter. There, the gate oxide involves either an in-situ passivation such as in the formation of $\mathrm{SiN}$ or the deposition of a high- $k$ (wide bandgap) oxide layer such as $\mathrm{Al}_{2} \mathrm{O}_{3}$ or $\mathrm{HfO}_{2}$ [40],[41]. For both MOSFET and HEMT configurations [42], a functional WBG oxide improves device functionalities, breaking the Boltzman limit for the transconductance and improving the switching speed of transistors by a negative capacitance effect [43],[44].

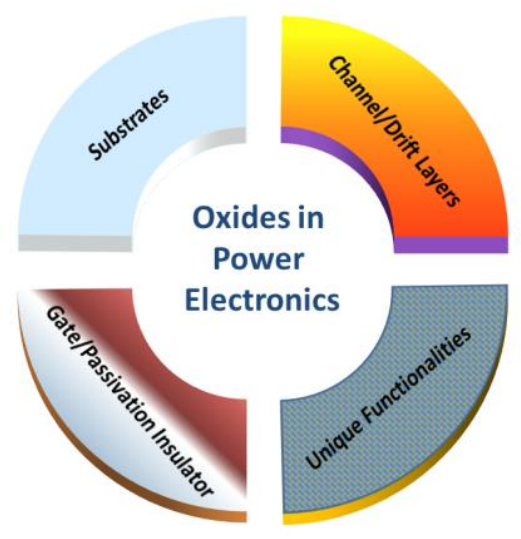

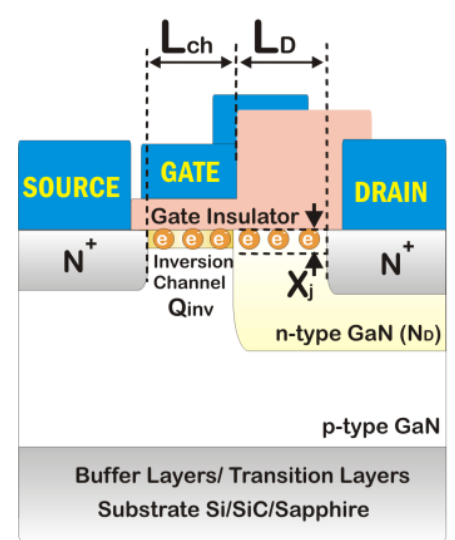

MOSFET

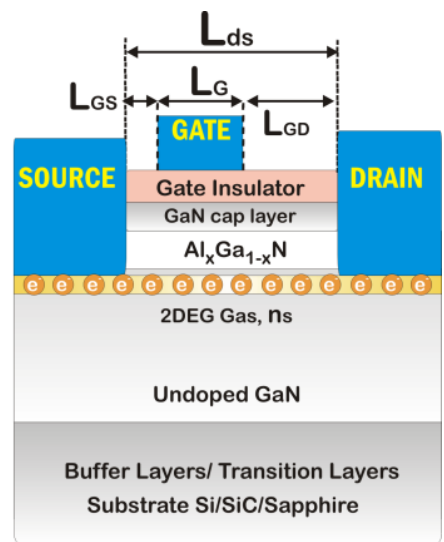

HEMT

Figure 5. Oxides have been traditionally used in power electronics devices as insulators; as passivation layers and/or gate oxides. Some other oxides, such as sapphire $\left(\mathrm{Al}_{2} \mathrm{O}_{3}\right)$, have also been used as the substrate platform for growing heteroepitaxial WBG semiconductors (gallium nitride in particular). Recently, with the rise of gallium oxide based technology, oxide layers are currently being intensively investigated as the semiconductor platform to define fourth power electronic devices platform (the platform which follows from silicon, silicon carbide and gallium nitride).

Current WBG materials of choice for power electronics (silicon carbide and gallium nitride) have bandgaps of $~ 3.2-3.5$ $\mathrm{eV}$ [4]. Recently, UWBG semiconductors are being investigated for the next generation of optoelectronic and power electronic applications. Up till now, the most investigated UWBG semiconductors are diamond, some nitrides (AlGaN, $\mathrm{AlN}$ and $\mathrm{BN}$ ) and a few oxides. Among the oxides, $\beta-\mathrm{Ga}_{2} \mathrm{O}_{3}$ is the only one with a UWBG for which it is possible to sufficiently modulate the conductivity (i.e. by doping) in order to define power electronic devices.

Current WBG semiconductors still suffer from important limitations with regards to the power electronics market - such as high defect densities, wafer scale-up issues, processing issues, limited breakdown voltages and relatively high costs and as a consequence it has taken around three decades to see the initial commercialization of $\mathrm{SiC}$ and $\mathrm{GaN}$. The technical challenges associated with $\mathrm{SiC}$ and $\mathrm{GaN}$, together with their relatively niche application compared to silicon, will probably mean that these power semiconductors will remain significantly more expensive for the foreseeable future. 
Furthermore, diamond as a power semiconductor, presents an additional challenge as it cannot be processed into devices readily and it most likely remain extremely expensive due to fundamental material growth scale-up constraints.

\subsection{Gallium Oxide, the newcomer}

A major advantage of the $\beta-\mathrm{Ga}_{2} \mathrm{O}_{3}$ is that wide area single crystals can be synthesised via several standard melt growth methods e.g. Czochralski (CZ) [45],[46], floating-zone (FZ) [47],[48] and edge-defined film-fed growth (EFG) [49]. This gives $\beta$ - $\mathrm{Ga}_{2} \mathrm{O}_{3}$ a huge advantage over $\mathrm{SiC}, \mathrm{GaN}$ and diamond in terms of mass production. Hence we would expect the cost of $\beta-\mathrm{Ga}_{2} \mathrm{O}_{3}$ based power electronics to become significantly lower over time and hence more competitive with silicon than their $\mathrm{SiC}$ and $\mathrm{GaN}$ based counterparts. Many thin film growth techniques have yielded epitaxial $\mathrm{Ga}_{2} \mathrm{O}_{3}$ (with the highest crystal quality being obtained by molecular beam epitaxy (MBE) [50] and halide vapour phase epitaxy (HVPE) [51]) and $n$-type doping technology is relatively well established. Si and $\mathrm{Sn}$ atoms are known to be shallow donors with small activation energies (60-80 meV), typically yielding electron densities in an acceptable power device drift region range of $10^{15}-10^{19} \mathrm{~cm}^{-3}[52]$.

\begin{tabular}{|c|c|c|c|c|c|c|}
\hline WBG & $\begin{array}{c}\text { Bandgap } \\
E_{g}[\mathrm{eV}]\end{array}$ & $\begin{array}{l}\text { Permitt. } \\
\varepsilon_{r}\left[\varepsilon_{0}\right]\end{array}$ & $\begin{array}{c}\text { Mobility } \\
\mu_{n}\left[\mathrm{~cm}^{2} / \mathrm{Vs}\right]\end{array}$ & $\begin{array}{l}\text { Crit. Field } \\
E_{c}[\mathrm{MV} / \mathrm{cm}]\end{array}$ & $\begin{array}{l}\text { BFOM x10 } \\
{\left[\mathrm{V}^{2} / \mathrm{Wcm}^{2}\right]}\end{array}$ & $\begin{array}{l}\text { Ther. Cond. } \\
k[\mathrm{~W} / \mathrm{mK}]\end{array}$ \\
\hline Si & 1.12 & 11.9 & 1240 & 0.3 & 8.8 & 145 \\
\hline $4 \mathrm{H}-\mathrm{SiC}$ & 3.20 & 9.7 & 980 & 3.1 & 6270 & 350 \\
\hline GaN & 3.40 & 10.4 & 1000 & 4.9 & 27900 & 140 \\
\hline$\beta-\mathrm{Ga}_{2} \mathrm{O}_{3}$ & 4.90 & 10.0 & 150 & 10.3 & 36300 & 27 \\
\hline Diamond & 5.50 & 5.7 & 2000 & 13.0 & 554000 & 3450 \\
\hline AIN & 6.00 & 9.8 & 426 & 15.4 & 336000 & 319 \\
\hline c-BN & 6.40 & 7.1 & 825 & 17.5 & 695000 & 2145 \\
\hline
\end{tabular}
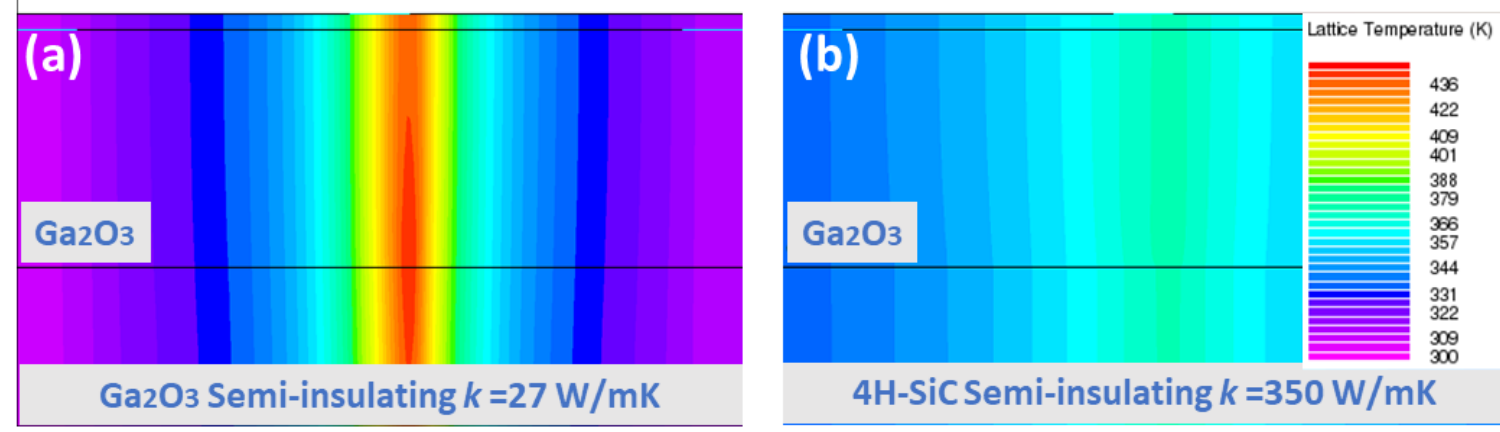

Figure 6. A summary of the main parameters to be considered for power devices (including Baliga's figure of merit. BFOM) of the most popular WBG semiconductors (adapted from [35]). Of note is the particularly poor thermal conductivity of gallium oxide. However, integration into devices, which provide heat sinks (such as silicon carbide) that limitation may be circumvented or, at least, moderated [61].

From a power devices perspective, $\mathrm{Ga}_{2} \mathrm{O}_{3}$ transistors and rectifiers have the potential to deliver excellent performance in based on their high breakdown voltage, high power capacity and comparatively low losses because of their unique material properties (e.g. high breakdown field, high electron mobility, etc.). Fig. 6 compares the unipolar limit of $\beta$ $\mathrm{Ga}_{2} \mathrm{O}_{3}$ and other major semiconductors, taking into account the relatively large breakdown electric field $\left(E_{B R}\right)$, which is expected to be on the order of $8 \mathrm{MV} / \mathrm{cm}$ [33]. The high $E_{B R}$ of $\mathrm{Ga}_{2} \mathrm{O}_{3}$, in particular, very significantly increases the 
suitability of a semiconductor material for power devices because Baliga's figure of merit [54] for power electronics is proportional to $E_{B R}{ }^{3}$, whilst only being linearly proportional to the bulk electron mobility $(\mu)$. The latter is estimated to be on the order of $300 \mathrm{~cm}^{2} / \mathrm{Vs}$ for $\beta-\mathrm{Ga}_{2} \mathrm{O}_{3}$. This suggests that the on-state losses can be an order of magnitude lower than those for $\mathrm{SiC}$ and $\mathrm{GaN}$ for a given breakdown voltage. Power device topologies have already been demonstrated on $\mathrm{Ga}_{2} \mathrm{O}_{3}$. $\mathrm{Ga}_{2} \mathrm{O}_{3}$ Schottky barrier diodes that sustained operation at over $2 \mathrm{kV}$ have been already demonstrated using singlecrystal $\beta-\mathrm{Ga}_{2} \mathrm{O}_{3}$ substrates [55]. Several transistor topologies have also been demonstrated including MESFET, MOSFETand GOOI (gallium-oxide-on-insulator) FETs [56]-[59]. Last two-years was a turning point for this meteoric emerging technology since researchers have demonstrated, both, $3.8 \mathrm{MV} / \mathrm{cm}$ critical field strength (surpassing GaN and $\mathrm{SiC}$ bulk theoretical field strengths) and high-performance nano-membrane $\beta$ - $\mathrm{Ga}_{2} \mathrm{O}_{3}$ GOOI-FETs with record drain currents of $600 \mathrm{~mA} / \mathrm{mm}$ [59]. Together with the recent demonstration of power and RF MOSFETs, this paves the way to transparent optoelectronic high voltage (power) devices [60].

There are, however, still several bottlenecks for the adoption of $\mathrm{Ga}_{2} \mathrm{O}_{3}$ as the WBG power semiconductor platform of choice [3],[35]. Perhaps some of the most important limitations are; (1) the low value of the thermal conductivity and (2) the difficulty of having bipolar operation since $p$-type doping has not been available. To address the first issue, it is possible to thin the substrate to reduce the heat losses or to integrate gallium oxide epitaxies onto semiconductors with higher thermal conductivities such as $\mathrm{SiC}$ [61]. Regarding the second issue, we have recently demonstrated that majority background $p$-type conduction is present in nominally undoped $\beta-\mathrm{Ga}_{2} \mathrm{O}_{3}$ thin films grown by Pulsed Laser Deposition [62] as shown below. If conductivities can be increased by doping this may herald a path to CMOS technology in UWBG oxides.
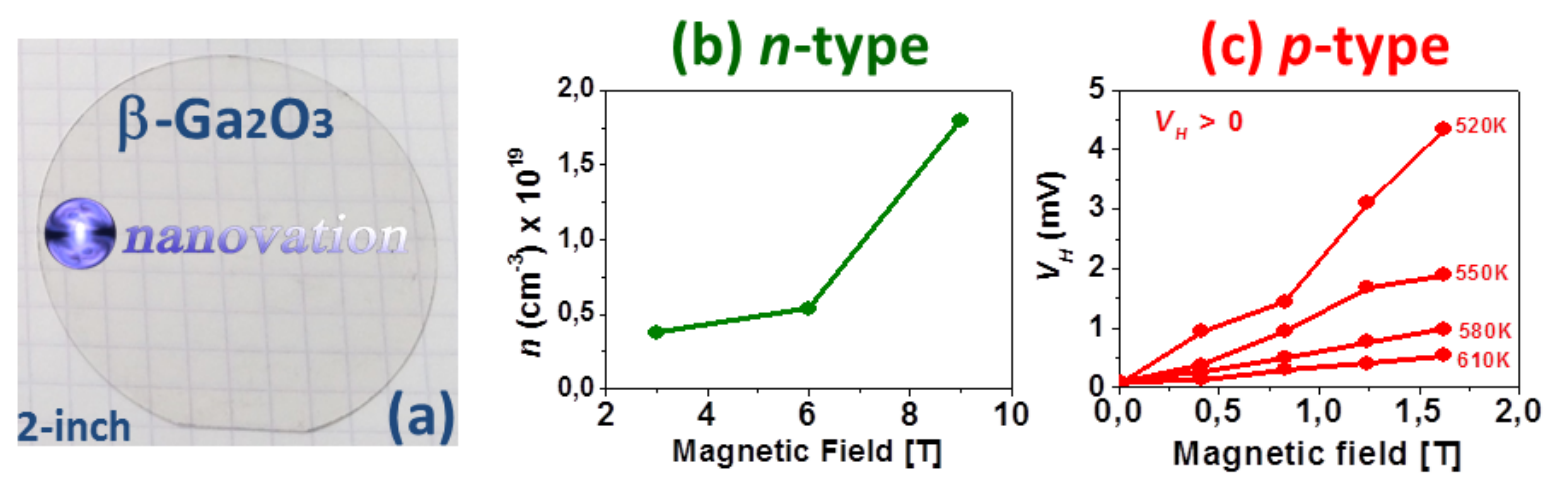

Figure 7. Evidence from high temperature Hall measurements of $\mathrm{n}$ and $\mathrm{p}$ type majority background conduction in nominally undoped $\beta$ - $\mathrm{Ga}_{2} \mathrm{O}_{3} /$ sapphire epiwafers. Having the possibility to fabricate both $p$ - and $n$-type $\beta$ - $\mathrm{Ga}_{2} \mathrm{O}_{3}$ would provide new avenues for high power and deep UV-optoelectronic devices [61].

\subsection{Towards an ultra-wide bandgap CMOS technology on Gallium Oxide}

All the $\mathrm{Ga}_{2} \mathrm{O}_{3}$ devices demonstrated thus far have been unipolar in nature (i.e. only $n$-type). In order to realize the full potential for WBG (opto)electronics $\beta$ - $\mathrm{Ga}_{2} \mathrm{O}_{3}$ will need bipolar junction based devices, for which $p$-type doping will be required. The current approach to form $\mathrm{p}-\mathrm{n}$ junction devices with $\beta-\mathrm{Ga}_{2} \mathrm{O}_{3}$ is by the formation of heterostructures of $\mathrm{n}$ type $\beta$ - $\mathrm{Ga}_{2} \mathrm{O}_{3}$ with known $p$-type semiconductors such as $p$-type oxides $\left(\mathrm{Cu}_{2} \mathrm{O}\right.$ [55], $\mathrm{Ir}_{2} \mathrm{O}_{3}$ [63], $\mathrm{NiO}_{\mathrm{x}}$ [64]) or acceptor doped semiconductors ( $\mathrm{Si}$ [65], SiC [66] or graphene [67]). Such heterojunctons have intrinsic disadvantages, however, because of crystallographic, thermal expansion and electronic band structure mismatches.

Currently, $p$-type wide bandgap oxides are in the form of binary copper oxides, $\mathrm{Cu}$-based delafosites, tin monoxide, nickel oxide or layered oxide-chalcogenides [68]. Each of these has a valence band made up of deep localized oxygen $2 p$ orbitals, which are responsible for poor hole transport in these materials [69]. $p$-type doping of $\beta-\mathrm{Ga}_{2} \mathrm{O}_{3}$ has been considered challenging-if not impossible due to a number of factors including the low absolute energy level of the 
valence band, the high effective mass of holes at the top of the valence band, self-trapping of holes and compensation from background n-type doping. Indeed, nominal undoped $\beta-\mathrm{Ga}_{2} \mathrm{O}_{3}$ is generally $n$-type, because of existence of (offstoichiometry-related) point defects acting as donors (e.g. oxygen vacancies and gallium interstitials) along with unintentional impurities (such as hydrogen or silicon) [70]. Furthermore, although p--type conductivity was theoretically predicted in gallium oxide by doping group I and II metals from the Mendeleyev table there is still not direct evidence to date of a shallow acceptor behaviour in $\beta-\mathrm{Ga}_{2} \mathrm{O}_{3}$ [71].

We have recently demonstrated [62] that nominally-undoped $\beta-\mathrm{Ga}_{2} \mathrm{O}_{3} / \mathrm{c}$-sapphire epiwafers exhibit a background majority $p$-type conduction. An activation energy of $0.56 \mathrm{eV}$ was extracted from temperature dependent Hall measurements and $\mathrm{V}_{\mathrm{Ga}}$ (or its' defect complexes) were proposed as acceptor candidates. This proposition was backed up by thermodynamic equilibrium calculations (Kroger theory) for the $\beta-\mathrm{Ga}_{2} \mathrm{O}_{3}$ (crystal) $-\mathrm{O}_{2}$ (gas) system, showing a "window" without oxygen vacancy $\mathrm{V}_{\mathrm{O}}$ compensation, which would allow hole conduction to emerge in $\beta-\mathrm{Ga}_{2} \mathrm{O}_{3}$. This situation may be related to the enthalpy of formation of Schottky defects in $\beta-\mathrm{Ga}_{2} \mathrm{O}_{3}$ which is relatively high (at approximately $3.68 \mathrm{eV}$ per vacancy). Thus, creation of donor oxygen vacancies is not as favorable as in (e.g.) $\mathrm{ZnO}$, which decreases compensation and makes hole conduction more favorable. This finding and understanding could be a crucial step towards realization of effective $p$-type doping. Of particular note is that all the other transparent oxides which show majority $p$-type conduction $\left(\mathrm{CuCrO}_{2}\right.$ and $\mathrm{Cu}_{2} \mathrm{SrO}_{2}, \mathrm{NiO}$ and $\left.\mathrm{FeTiO}_{3}\right)$ have much lower bandgaps $(\sim 3.2-$ $3.5 \mathrm{eV})$ than $\beta-\mathrm{Ga}_{2} \mathrm{O}_{3}(\sim 4.9 \mathrm{eV})$.

The demonstration of $p$-type $\mathrm{Ga}_{2} \mathrm{O}_{3}$ doping would allow the definition of $\mathrm{Ga}_{2} \mathrm{O}_{3}$ p- $n$ junction building blocks and therefore the equivalent of any conventional silicon-based devices could, in theory, be engineered; including MOSFETs, (complementary) CMOS logic or bipolar devices such as p-i-n diodes or insulator gate bipolar transistors (IGBT) [72]. P-type gate depletion is also a widely-applied strategy to make unipolar high mobility transistors normally-off in gallium nitride technology [73]. Therefore, $p$-type gates may also be applied, in principle, in gallium oxide based HEMTs [74], [75]. In optoelectronics applications, the demonstration of $p$-type $\beta-\mathrm{Ga}_{2} \mathrm{O}_{3}$ is also relevant. A high performance, UWBG $p$-type TCO would leverage the great promise of oxides for transparent electronics and optoelectronics. Owing to their UWBG [76], a particularly important future field of application is as transparent conducting electrodes for emerging deep ultraviolet light emitting diodes and sensors.

\section{CONCLUSIONS}

The future can only be bright for WBG and UWBG oxides because of the large number of unique features they can bring as key enabler materials for a more sustainable society. Oxides are increasingly being incorporated into the mainstream of solid-state electronic devices which are the building blocks of the internet of things. Oxides are also increasingly investigated as a material for energy generation (particularly in solar cells), conversion and storage systems. Here, we have reviewed some of our recent results in the context of the current state-of-the-art so as to provide a glimpse of the enormous possibilities that are emerging. We have shown that functional reversibly polarizable oxides can extend photogenerated electric fields to several $\mathrm{MV} / \mathrm{cm}$ and, thus, their associated photovoltages to several hundreds of volts in a micron-thick slab. We have also shown that they can act as switchable interfaces on solar cells so enabling the formation of compact solar transistors or solaristors. These novel functions provide the building blocks for innovative topologies in the conversion and control of photovoltaic systems. When combined with UWBG conductive oxides ( such $\beta-\mathrm{Ga}_{2} \mathrm{O}_{3}$ ) these functionalities are further extended to broader wavelength ranges (i.e. transparency over the full solar spectrum and into the UVC) so further improving their efficiency and applicability. Our recent demonstration of $p$-type doping in $\beta$ $\mathrm{Ga}_{2} \mathrm{O}_{3}$ was also overviewed, along with a consideration of the resulting perspectives for the development of transparent UWBG $\beta-\mathrm{Ga}_{2} \mathrm{O}_{3} p-n$ junctions as building blocks for devices going beyond those used in traditional silicon-based power electronics (e.g. monolithic CMOS logic or bipolar devices which could integrate smart zero-emissions photovoltaic systems). 


\section{AKNOWLEDGEMENTS}

APT acknowledges Agencia Estatal de Investigación (AEI) and Fondo Europeo de Desarrollo Regional under contract ENE2015-74275-JIN. The ICN2 is funded by the CERCA programme / Generalitat de Catalunya and by the Severo Ochoa programme of the Spanish Ministry of Economy, Industry and Competitiveness (MINECO, grant no. SEV-20130295).

\section{REFERENCES}

[1] D. S. Ginley, H. Hosono, and D. C. Paine (Editors), [Handbook of Transparent Conductors], Springer, Golden, CO, USA, (2011).

[2] X. Yu, T. J. Marks and A. Facchetti, "Metal oxides for optoelectronic applications," Nat. Mater. 15, 383-396 (2016).

[3] D. C. Look, and K. D. Leedy, "Degenerate $\mathrm{Ga}_{2} \mathrm{O}_{3}$ : a highly-conductive TCO with an extremely wide bandgap," SPIE Photonic West Proceedings, San Francisco, paper 10533-37 (2018).

[4] S. J. Pearton, J. Yang, P. H. Cary, F. Ren, J. Kim, M. J. Tadjer, and M. A. Mastro, "A review of $\mathrm{Ga}_{2} \mathrm{O}_{3}$ materials, processing, and devices," Appl. Phys. Rev. 5, 011301 (2018).

[5] J. Millán, P. Godignon, X. Perpiñà, A. Pérez-Tomás and J. Rebollo, "A Survey of Wide Bandgap Power Semiconductor Devices,” IEEE Trans. Power Elec. 29, 2155 (2014).

[6] H. von Wenckstern, "Group-III sesquioxides: growth, physical properties and devices," Adv. Electron. Mater. 93, 1600350 (2017).

[7] J. Kim, T. Sekiya, N. Miyokawa, N. Watanabe, K. Kimoto, K. Ide, Y. Toda, S. Ueda, N. Ohashi, H. Hiramatsu, H. Hosono and T. Kamiya, "Conversion of an ultra-wide bandgap amorphous oxide insulator to a semiconductor," NPG Asia Materials 9, e359 (2017).

[8] See for example, G. H. Haertling, "Ferroelectric Ceramics: History and Technology," J. Am. Ceram. Soc. 82, 797818 (1999); P. K. Panda and B. Sahoo, "PZT to Lead Free Piezo Ceramics: A Review," Ferroelectrics 474, 128-143, (2015).

[9] See for example, Z. Hameiri, "Photovoltaics literature survey (No. 125)," Progress in Photovoltaics: Research and Applications, 24, 405-407 (2016).

[10] T. Minami, Y. Nishi and T. Miyata, "Efficiency enhancement using a $\mathrm{Zn}_{1-} \mathrm{Ge}_{\mathrm{x}}-\mathrm{O}$ thin film as an $n$-type window layer in $\mathrm{Cu}_{2} \mathrm{O}$-based heterojunction solar cells," Appl. Phys. Express, 9, 052301 (2016).

[11] R. Nechache, C. Harnagea, S. Li, L. Cardenas, W. Huang, J. Chakrabartty and F. Rosei, "Bandgap tuning of multiferroic oxide solar cells," Nat. Photonics 9, 61 (2015).

[12]D. Tiwari, D. J. Fermin, T. K. Chaudhuri, and A. Ray, "Solution Processed Bismuth Ferrite Thin Films for AllOxide Solar Photovoltaics," J. Phys. Chem. C 119, 5872-5877 (2015).

[13] K. Yao, B. K. Gan, M. Chen and S. Shannigrahi, "Large photo-induced voltage in a ferroelectric thin film with inplane polarization," Appl. Phys. Lett. 87, 212906 (2005).

[14] S. Y. Yang, J. Seidel, S. J. Byrnes, P. Shafer, C. H. Yang, M. D. Rossell, P. Yu, Y. H. Chu, J. F. Scott and J. W. Ager, "Above-bandgap voltages from ferroelectric photovoltaic devices," Nat. Nanotechnol. 5, 143 (2010).

[15] A. Pérez-Tomás, M. Lira-Cantú and G. Catalan, "Above-Bandgap Photovoltages in Antiferroelectrics," Adv. Mater. 28, 9644 (2016).

[16] A. Pérez-Tomás, A. Lima, Q. Billon, I. Shirley, G. Catalan and M. Lira-Cantú, "A solar transistors and photoferroelectric memory," Adv. Func. Mater. 1707099 (2018). https://doi.org/10.1002/adfm.201707099

[17]F. Zheng, Y. Xin, W. Huang, J. Zhang, X. Wang, M. Shen, W. Dong, L. Fang, Y. Bai, X. Shen, J. Hao, “Above 1\% efficiency of a ferroelectric solar cell based on the $\mathrm{Pb}(\mathrm{Zr}, \mathrm{Ti}) \mathrm{O}_{3}$ film," J. Mater. Chem. A, 2, 1363-1368 (2014).

[18] D. Cao, C. Wang, F. Zheng, W. Dong, L. Fang, M. Shen, "High-efficiency ferroelectric-film solar cells with an ntype $\mathrm{Cu}_{2} \mathrm{O}$ cathode buffer layer," NanoLett. 12, 2803-2809 (2012).

[19] A. Pérez-Tomás, et al. Under review

[20] B. K. Meyer, A. Polity, D. Reppin, M. Becker, P. Hering, P. J. Klar, Th. Sander, C. Reindl, J. Benz, M. Eickhoff, C. Heiliger, M. Heinemann, J. Bläsing, A. Krost, S. Shokovets, C. Müller, and C. Ronning, "Binary copper oxide semiconductors: From materials towards devices," Phys. Status Solidi B 249, 1487-1509 (2012).

[21] S. Rühle, A. Y. Anderson, H-N. Barad, B. Kupfer, Y. Bouhadana, E. R-Hodesh, and A. Zaban, "All-oxide photovoltaics," J. Phys. Chem. Lett. 3, 3755-3764 (2012). 
[22]I. Sullivan, B. Zoellner, and P. A. Maggard, "Copper(I)-Based p-Type Oxides for Photoelectrochemical and Photovoltaic Solar Energy Conversion," Chem. Mater. 28, 5999-6016 (2016).

[23] K. Ellmer, "Past achievements and future challenges in the development of optically transparent electrodes," Nat. Photonics 6, 809-817 (2012).

[24] C-C. Chueh, C-Z. Lia and A. K.-Y. Jen, "Recent progress and perspective in solution-processed Interfacial materials for efficient and stable polymer and organometal perovskite solar cells," Energy Environ. Sci. 8, 1160-1189 (2015).

[25] Y. Reyna, A. Pérez-Tomás, A. Mingorance, M. Lira-Cantú, [Stability of Molecular Devices: Halide Perovskite Solar Cells, Molecular Devices for Solar Energy Conversion and Storage], Springer, Singapore 477-531 (2018). https://link.springer.com/chapter/10.1007/978-981-10-5924-7_13

[26] P. J. Sturman and V. M. Fridkin, [Photovoltaic and Photo-refractive Effects in Noncentrosymmetric Materials], Gordon and Breach Science Publishers, (1992).

[27] W. Shockley, and H. J. Queisser, "Detailed balance limit of efficiency of p-n junction solar cells," J. Appl. Phys. 32, 510 (1961).

[28] A. Pérez-Tomás, A. Mingorance, D. Tanenbaum and M. Lira-Cantú, [Metal Oxides in Photovoltaics: All-Oxide, Ferroic, and Perovskite Solar Cells (Ch. 8) in The Future of Semiconductor Oxides in Next-Generation Solar Cells], Elsevier, Amsterdam, Netherlands 267-356 (2018). https://doi.org/10.1016/B978-0-12-811165-9.09989-0

[29] L. Z. Tan, F. Zheng, S. M. Young, F. Wang, S. Liu and A. M. Rappe, "Shift current bulk photovoltaic effect in polar materials-hybrid and oxide perovskites and beyond," npj Comput. Mater. 2, 16026 (2016).

[30] J. E. Spanier, V. M. Fridkin, A. M. Rappe, A. R. Akbashev, A. Polemi, Y. Qi, Z. Gu, S. M. Young, C. J. Hawley, D. Imbrenda, G. Xiao, A. L. Bennett-Jackson and C. L. Johnson, "Power conversion efficiency exceeding the Shockley-Queisser limit in a ferroelectric insulator," Nat. Photonics, 10, 611 (2016).

[31]J. E. Lilienfeld, patents US1745175A (1925) and US1900018 (1928); J. Bardeen, W. H. Brattain patent US2524035A (1948) and W. Shockley patent US2569347A (1948); I. Ferain, C. A. Colinge, J.-P. Colinge, Nature 479, 310-316 (2011); J. A. del Alamo, Nature 479, 317-323 (2011).

[32] D. Kufer, G. Konstantatos, "Photo-FETs: Phototransistors Enabled by 2D and 0D Nanomaterials," ACS Photonics 3, 2197-2210 (2016); F. P. García de Arquer, A. Armin, P. Meredith, E. H. Sargent, "Solution-processed semiconductors for next-generation photodetectors," Nat. Rev. Mat. 2, 16100 (2017); H. Wang, D. H. Kim, "Perovskite-based photodetectors: materials and devices," Chem. Soc. Rev. 46, 5204 (2017).

[33] S. Fujita, "Wide-bandgap semiconductor materials: For their full bloom," Jpn. J. Appl. Phys 54, 030101 (2015).

[34] S. J. Pearton, C. R. Abernathy, M. E. Overberg, G. T. Thaler, D. P. Norton N. Theodoropoulou, A. F. Hebard, Y. D. Park, F. Ren, J. Kim and L. A. Boatner, "Wide band gap ferromagnetic semiconductors and oxides," J. Appl. Phys. 93, 1-13 (2002).

[35] J. Y. Tsao, S. Chowdhury, M. A. Hollis, D. Jena, N. M. Johnson, K. A. Jones, R. J. Kaplar, S. Rajan, C. G. Van de Walle, E. Bellotti, C. L. Chua, R. Collazo, M. E. Coltrin, J. A. Cooper, K. R. Evans, S. Graham, T. A. Grotjohn, E. R. Heller, M. Higashiwaki, M. S. Islam, P. W. Juodawlkis, M. A. Khan, A. D. Koehler, J. H. Leach, U. K. Mishra, R. J. Nemanich, R. C. N. Pilawa-Podgurski, J. B. Shealy, Z. Sitar, M. J. Tadjer, A. F. Witulski, M. Wraback, and J. A. Simmons, "Ultrawide-Bandgap Semiconductors: Research Opportunities and Challenges," Adv. Electron. Mater. 4, 1600501 (2018).

[36] S. M. Sze, K. K. Ng, [Physics of semiconductor devices], John Wiley \& Sons, Inc., Hoboken, New Jersey, USA, (2006).

[37] A. Pérez-Tomás, P. Brosselard, J. Hassan, X. Jordà, P. Godignon, M. Placidi, A. Constant, J. Millán and J. P. Bergman, "Schottky versus bipolar 3.3 kV SiC diodes," Semicond. Sci. Technol. 23, 125004 (2008).

[38] A. Pérez-Tomás, P. Brosselard, P. Godignon, J. Millán, N. Mestres, M. R. Jennings, J. A. Covington, P. A. Mawby, "Field-effect mobility temperature modeling of $4 \mathrm{H}-\mathrm{SiC} 4 \mathrm{H}-\mathrm{SiC}$ metal-oxide-semiconductor transistors," J. App. Phys. 100, 114508 (2006).

[39] A. Pérez-Tomás, M. Placidi, N. Baron, S. Chenot, Y. Cordier, J. C. Moreno, A. Constant, P. Godignon, and J. Millán, "GaN transistor characteristics at elevated temperatures," J. App. Phys. 106, 074519 (2009).

[40] A. Fontserè, A. Pérez-Tomás, V. Banu, P. Godignon, J. Millán, H. de Vleeschouwer, J. M. Parsey and P. Moens, "A $\mathrm{HfO}_{2}$ based $800 \mathrm{~V} / 300^{\circ} \mathrm{C}$ Au-free AlGaN/GaN-on-Si HEMT Technology," Proceedings of the 2012 24th International Symposium on Power Semiconductor Devices and ICs 3-7 June 2012 - Bruges, Belgium, 37-40 (2012).

[41] A. Pérez-Tomás, A. Fontserè, M.R. Jennings, P.M. Gammon, "Modeling the effect of thin gate insulators $\left(\mathrm{SiO}_{2}\right.$, $\mathrm{SiN}, \mathrm{Al}_{2} \mathrm{O}_{3}$ and $\mathrm{HfO}_{2}$ ) on $\mathrm{AlGaN} / \mathrm{GaN}$ HEMT forward characteristics grown on $\mathrm{Si}$, sapphire and $\mathrm{SiC}$," Mater Sci Semicond Process. 16, 1336-1345 (2013). 
[42] A. Fontserè, A. Pérez-Tomás, M. Placidi, P. Fernández-Martínez, N. Baron, S. Chenot, Y. Cordier, J. C. Moreno, P. M. Gammon, M. R. Jennings, "Temperature dependence of Al/Ti-based Ohmic contact to GaN devices: HEMT and MOSFET," Microelectronic Engineering 88, 3140-3144 (2011).

[43] S. Salahuddin, and S. Datta, "Use of Negative Capacitance to Provide Voltage Amplification for Low Power Nanoscale Devices," Nano Letters 8, 405 (2008).

[44] P. Zubko, J. C. Wojde, M. Hadjimichael, S. Fernandez-Pena, A. Sené, I. Luk'yanchuk, J-M. Triscone, and J. Íñiguez, "Negative capacitance in multidomain ferroelectric superlattices," Nature 534, 524 (2016).

[45]Z. Galazka, K. Irmscher, R. Uecker, R. Bertram, M. Pietsch, A. Kwasniewski, M. Naumann, T. Schulz, R. Schewski, D. Klimm and M. Bickermann, "On the bulk $\beta-\mathrm{Ga}_{2} \mathrm{O}_{3}$ single crystals grown by the Czochralski method," J. Cryst. Growth 404, 184 (2014).

[46] Y. Tomm, P. Reiche, D. Klimm, T. Fukuda, “Czochralski grown $\mathrm{Ga}_{2} \mathrm{O}_{3}$ crystals,” J. Cryst. Growth 220 , 510 (2000).

[47] S. Ohira, M. Yoshioka, T. Sugawara. K. Nakajima, T. Shishido, "Fabrication of hexagonal GaN on the surface of $\beta$ $\mathrm{Ga}_{2} \mathrm{O}_{3}$ single crystal by nitridation with $\mathrm{NH}_{3}$," Thin Solid Films 496, 53 (2006).

[48] E. G. Víllora, K. Shimamura, Y. Yoshikawa, K. Aoki, N. Ichinose, "Large-size $\beta-\mathrm{Ga}_{2} \mathrm{O}_{3}$ single crystals and wafers," J. Cryst. Growth 270, 420 (2004).

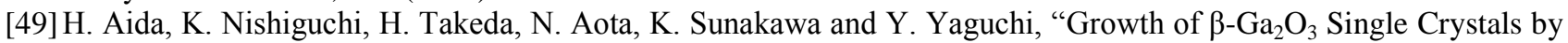
the Edge-Defined, Film Fed Growth Method,” Jpn. J. Appl. Phys. 47, 8506 (2008).

[50] M. Higashiwaki, K. Sasaki, A. Kuramata, T. Masui and S. Yamakoshi, "Development of gallium oxide power devices," Phys. Status Solidi A 211, 21 (2014).

[51] H. Murakami, K. Nomura, K. Goto, K. Sasaki, K. Kawara, Q. T. Thieu, R. Togashi, Y. Kumagai, M. Higashiwaki, A. Kuramata, "Homoepitaxial growth of $\beta-\mathrm{Ga}_{2} \mathrm{O}_{3}$ layers by halide vapor phase epitaxy," Appl. Phys. Express 8, 015503 (2015).

[52] H. He, R. Orlando, M. A. Blanco, R. Pandey, E. Amzallag, I. Baraille, and M. Réra, "First-principles study of the structural, electronic, and optical properties of $\mathrm{Ga}_{2} \mathrm{O}_{3}$ in its monoclinic and hexagonal phases," Phys. Rev. B 74, 195123 (2006).

[53] H. Peelaers, and C. G. Van de Walle, "Brillouin zone and band structure of $\beta-\mathrm{Ga}_{2} \mathrm{O}_{3}$," Phys. Status Solidi B 252, 828 (2015).

[54] B. J. Baliga, "Power semiconductor device figure of merit for high-frequency applications," IEEE Electron. Dev. Let. 10, 455 (1989).

[55] T. Watahiki, Y. Yuda, A. Furukawa, M. Yamamuka, Y. Takiguchi, and S. Miyajima, "Heterojunction $p-\mathrm{Cu}_{2} \mathrm{O} / n-$ $\mathrm{Ga}_{2} \mathrm{O}_{3}$ diode with high breakdown voltage," Appl. Phys. Lett. 111, 222104 (2017).

[56] M. Higashiwaki, K. Sasaki, A. Kuramata, T. Masui, and S. Yamakoshi, "Gallium oxide $\left(\mathrm{Ga}_{2} \mathrm{O}_{3}\right) \mathrm{metal}$ semiconductor field-effect transistors on single-crystal $\beta-\mathrm{Ga}_{2} \mathrm{O}_{3}(010)$ substrates," Appl. Phys. Lett. 100, 013504 (2012).

[57] W. S. Hwang, A. Verma, H. Peelaers, V. Protasenko, S. Rouvimov, H. G. Xing, A. Seabaugh, W. Haensch, C. Van de Walle, Z. Galazka, M. Albrecht, R. Fornari, and D. Jena, "High-voltage field effect transistors with widebandgap $\beta-\mathrm{Ga}_{2} \mathrm{O}_{3}$ nanomembranes," Appl. Phys. Lett. 104, 203111 (2014).

[58] M. J. Tadjer, N. A. Mahadik, V. D. Wheeler, E. R. Glaser, L. Ruppalt, A. D. Koehler, K. D. Hobart, C. R. Eddy Jr. and F. J. Kub, “A (001) $\beta-\mathrm{Ga}_{2} \mathrm{O}_{3}$ MOSFET with +2.9 V Threshold Voltage and $\mathrm{HfO}_{2}$ Gate Dielectric," ECS J. Solid State Sci. Technol. 5, 468 (2016).

[59] A. J. Green, K. D. Chabak, E. R. Heller, R. C. Fitch, M. Baldini, A. Fiedler, K. Irmscher, G. Wagner, Z. Galazka, S. E. Tetlak, A. Crespo, K. Leedy, and G. H. Jessen, “3.8-MV/cm Breakdown Strength of MOVPE-Grown Sn-Doped $\beta-\mathrm{Ga}_{2} \mathrm{O}_{3}$ MOSFETs,” IEEE Electron. Dev. Let. 37, 902 (2016).

[60] A. J. Green, K. D. Chabak, M. Baldini, N. Moser, R. Gilbert, R. C. Fitch, G. Wagner, Z. Galazka, J. McCandless, A. Crespo, K. Leedy, and G. H. Jessen, “ $\beta-\mathrm{Ga}_{2} \mathrm{O}_{3}$ MOSFETs for radio frequency operation,” IEEE Electron. Dev. Let. 38, 790 (2017).

[61] S. A. O. Russell, A. Pérez-Tomás, C. F. McConville, D. P. Hamilton, C. A. Fisher, P. A. Mawby, and M. R. Jennings, "Heteroepitaxial Beta- $\mathrm{Ga}_{2} \mathrm{O}_{3}$ on $4 \mathrm{H}-\mathrm{SiC}$ for an FET With Reduced Self Heating," IEEE J. Electron Devices Soc. 5, 256-261 (2017).

[62] E. Chikoidze, A. Fellous, A. Pérez-Tomás, G. Sauthier, T. Tchelidze, C. Ton-That, T. Thanh Huynh, M. Phillips, S. Russell, M. Jennings, B. Berini, F. Jomard, Y. Dumont, "P-type $\beta$-gallium oxide: A new perspective for power and optoelectronic devices," Materials Today Physics 3, 118-126 (2017).

[63] FLOSFIA Inc. website, https://www.pntpower.com/flosfia-galo-power/, 2017 
[64] Y. Kokubun, S. Kubo, Sh. Nakagomi, "All-oxide $p-n$ heterojunction diodes comprising $p$-type NiO and $n$-type $\beta$ $\mathrm{Ga}_{2} \mathrm{O}_{3}$," Appl. Phys. Express 9, 091101 (2016).

[65] X. C. Guo, N. H. Hao, D.Y. Guo, Z. P. Wu, Y. H. An, X. L. Chu, L. H. Li, P. G. Li, M. Lei, W. H. Tang, " $\beta-$ $\mathrm{Ga}_{2} \mathrm{O}_{3} / p$-Si heterojunction solar-blind ultraviolet photodetector with enhanced photoelectric responsivity," J. Alloys Compd. 660, 136-140 (2016).

[66] Y. Qu, Z. Wu, M. Ai, D. Guo, Y. An, H. Yang, L. Li, W. Tang, "Enhanced $\mathrm{Ga}_{2} \mathrm{O}_{3} / \mathrm{SiC}$ ultraviolet photodetector with graphene top electrodes," J. Alloys Comp. 680, 247-251 (2016).

[67] W.-Y. Kong, G.-A. Wu, K.-Y. Wang, T.-F. Zhang, Y.-F. Zou, D.-D. Wang, L.-B. Luo, "Graphene- $\beta-\mathrm{Ga}_{2} \mathrm{O}_{3}$ Heterojunction for Highly Sensitive Deep UV Photodetector Application," Adv. Mater. 28, 10725-10731 (2016).

[68] K. H. L. Zhang, K. Xi, M. G. Blamire and R. G. Egdell, "P-type transparent conducting oxides," J. Phys. Condens. Matter. 28, 383002 (2016).

[69]Z. Wang, P. K. Nayak, J. A. Caraveo-Frescas, H. N. Alshareef, "Recent Developments in p-Type Oxide Semiconductor Materials and Devices," Adv. Mater. 28, 3831-3892 (2016).

[70] M. Higashiwaki, K. Sasaki, H. Murakami, Y. Kumagai, A. Koukitu, A. Kuramata, T. Masui S. Yamakoshi, "Recent progress in $\mathrm{Ga}_{2} \mathrm{O}_{3}$ power devices," Semicond. Sci. Technol. 31, 034001 (2016).

[71]C. Tang, J. Sun, N. Lin, Z. Jia, W. Mu, X. Tao, X. Zhao, "Electronic structure and optical property of metal-doped $\mathrm{Ga}_{2} \mathrm{O}_{3}$ : a first principles study," RSC Adv. 6, 78322 (2016).

[72] R. Pérez, D. Tournier, A. Pérez-Tomás, P. Godignon, N. Mestres, J. Millán, "Planar edge termination design and technology considerations for 1.7-kV 4H-SiC PiN diodes," IEEE Trans. Electron. Devices 52, 2309 (2005).

[73] Y. Uemoto, M. Hikita, H.Ueno, H. Matsuo, H. Ishida, M. Yanagihara, T. Ueda, T. Tanaka, and D. Ueda, "Gate injection transistor (GIT) - A normally-off $\mathrm{AlGaN} / \mathrm{GaN}$ power transistor using conductivity modulation," IEEE Trans. Electron Devices 54, 3393-3399 (2007).

[74]O. Takayoshi, K. Yuji, K. Naoto, K. Akito, Y. Shigenobu, F. Shizuo, O. Toshiyuki, K. Makoto, "Carrier confinement observed at modulation-doped $\beta-\left(\mathrm{Al}_{\mathrm{x}} \mathrm{Ga}_{1-\mathrm{x}}\right)_{2} \mathrm{O}_{3} / \mathrm{Ga}_{2} \mathrm{O}_{3}$ heterojunction interface," Appl. Phys. Exp. 10, 035701 (2017).

[75] S. Krishnamoorthy, Z. Xia, C. Joishi, Y. Zhang, J. McGlone, J. Johnson, M. Brenner, A. R. Arehart, J. Hwang, S. Lodha, and S. Rajan, "Modulation-doped $\beta-\left(\mathrm{Al}_{0.2} \mathrm{Ga}_{0.8}\right)_{2} \mathrm{O}_{3} / \mathrm{Ga}_{2} \mathrm{O}_{3}$ field-effect transistor," Appl. Phys. Lett. 111, 023502 (2017).

[76] M. Orita, H. Ohta, M. Hirano, H. Hosono, "Deep Ultraviolet Transparent Conductive $\beta-\mathrm{Ga}_{2} \mathrm{O}_{3}$ Thin Films," Appl. Phys. Lett. 77, 4166 (2000). 